\title{
Label Perception of Frozen Ready-to-Eat Products and Frozen Not-Ready-to-Eat Product
}

By

\author{
Conic Cheung ${ }^{1}$, Dale Chen ${ }^{2}$, Helen Heacock ${ }^{3}$, Lorraine McIntyre ${ }^{4}$ \\ B. Tech in Environmental Health (Public Health Inspection) \\ British Columbia Institute of Technology, 2019
}

\author{
PROJECT SUBMITTED IN PARTIAL FULFILLMENT OF THE REQUIREMENTS \\ FOR THE DEGREE OF \\ Bachelor of Technology in Environmental Health \\ (C) Conic Cheung \\ BRITISH COLUMBIA INSTITUTE OF TECHNOLOGY
}

April 2019

All rights reserved, this work may not be reproduced in whole or in part, by photocopy or other means, without permission of the author

\footnotetext{
${ }^{1}$ Lead Author, B. Tech Student, School of Health Sciences, British Columbia Institute of Technology, 3700 Willingdon Ave, Burnaby, BC V5G 3H2

${ }^{2}$ Supervisor, School of Health Sciences, British Columbia Institute of Technology, 3700 Willingdon Ave, Burnaby, BC V5G 3H23

${ }^{3}$ Supervisor, School of Health Sciences, British Columbia Institute of Technology, 3700 Willingdon Ave, Burnaby, BC V5G 3H23

${ }^{4}$ Project Mentor, Food Safety Specialist, British Columbia Centre for Disease Control, 655 West 12th Avenue, Vancouver, BC V5Z 4R4
} 
"The views expressed in this paper are those of the author and do not necessarily reflect the official policy, position or views of BCIT, the Environmental Health Program or its faculty." 


\begin{abstract}
Background: Frozen meals are popularized in recent years due to their ease of preparation. This convenience factor greatly benefits busy workers who simply lack the time to cook a full meal. However, the risk of misidentifying these frozen products as cooked when they are in fact, raw, can lead to devastating consequences. This is important especially when the products are improperly prepared and undercooked. Some significant examples in recent years includes the Salmonella cases associated with frozen raw breaded chicken. These cases are partly due to the inadequate cooking of the product, as a result of misidentifying them as cooked even though they are raw. The purpose of this project is to determine how well the public can determine if a frozen product is cooked or raw based on the front side of the packaging, which is the first visuals that will be presented to the consumers in store.
\end{abstract}

Methods: An electronic survey was conducted for Canadian residents to determine whether they can accurately interpret if a product is cooked or raw based on the front packaging. The survey also determines if the respondent's age, gender, average number of supermarket visits in a week, and level of education will affect the accuracy of their interpretations. The survey was created and hosted online with SurveyMonkey, and distributed out in Reddit. The results are analyzed using the statistical software, NCSS 12.

Results: Chi-square tests indicated no significant difference between the demographics groups and the accuracy of the label interpretations by the respondents. Five different products; chicken pot pie, fish fillets, breaded chicken wings, poutine bites, and tourtiere pie, were chosen for identification, each with their own label statements, respectively; "cook thoroughly", "uncooked", "fully cooked", "heat thoroughly" and one with no label statement. The fish fillets, poutine bites and the tourtiere pie had the most varied answers from the respondents. The poutine bites and tourtiere pie had the majority of the respondents selecting the wrong answer or being unsure. The fish fillets had the majority choosing the correct answer, but given the simplicity of the label "uncooked", it was surprising that only $45 \%$ of the respondents chose "require additional cooking".

Additionally, a few of the open ended comments from respondents indicate some desire for labels clarity in regards to fonts and color on the packaging, as well as having clear, standardized statements that clearly identifies the products as cooked or raw. However, there are some comments that indicate the current labels are adequate, and some comments mentioning about labelling on the back of the box. 
Conclusion: Based on the results of the study, it would appear that the demographic groups selected have no effect on the accuracy of label identifications of frozen products. The study also indicates that there is preference from the public to favours clear and straightforward labelling statements. The study identifies potential problems with some ambiguity in the label statements (or lack of label statements), and some potential issues with the noticeability of the statements to the consumers.

Keywords: Frozen Ready-to-Eat Products, Frozen Products, Labelling, Survey, Frozen Meals, Labels 


\section{Introduction}

The biggest advantage of frozen food

products is the convenience that it offers to its consumer. However, contrary to what most may believe, partly due to the visual representation of such products in the packaging and in the way they are presented, frozen food products are not always precooked. The result of this misperception and misinterpretation of packaging labels on frozen food products is what leads to inadequate cooking and improper food handling. The front of the packaging is the first visual representation of the product that a consumer will see when they are shopping. It is important that information of the product is available promptly to the consumers before they make the purchase, this is the "first line of defense" in regards to the consumers properly preparing the product. The wide spread availability of these products in supermarkets magnifies this problem, causing a widespread health problem. It is essential that consumers are able to identify if the frozen product is cooked or not in order to prevent foodborne illness from improper food handling. The objective of the study is to assess the ability of consumers to accurately interpret the product's labels in regards to it being cooked or not, based on the front of the package.

\section{Literature Review}

\section{Health Impact of Frozen Meals}

Ready-to-eat meals is at a rising trend in terms of sales (Ready Meals in Canada, 2015), and in terms of being consumed for Canadians (Levesque, 2017), composing a significant portion of the population's diet. However, it is important to note that frozen meals are not always precooked, this causes them to lack a final processing step that reduces foodborne pathogens to a safe level before being consumed (Tang et al., 2018). This lack of a final cooking step causes the potential for foodborne pathogens to persist on the food, some common ones are Bacillus cereus, Clostridium botulinum, Clostridium perfringens, Escherichia coli O157:H7, Listeria monocytogenes, Salmonella sp., Staphylococcus aureus, Hepatitis A, Norovirus, and Calicivirus (Tang et al., 2018). These foodborne pathogens can cause a variety of diseases such as gastroenteritis, salmonellosis, listeriosis, and botulism. These diseases also bring about symptoms such as bloody diarrhea, fever, vomiting and potentially hospitalization and death (Kalyoussef \& Feja, 2014).

\section{Misconceptions \& Outbreaks}

Multiple outbreaks occurred in Canada in recent years due to frozen food products (Canadian Food Inspection Agency, 2018; Associated Press 2018), including frozen raw breaded chicken (Canadian Food Inspection Agency, 2018). Despite changes in regulations to have the products labelled 
when they are visually represented as being ready-to-eat, there's still numerous recalls occurring due to the misinterpretation of these products as being precooked (Canadian Food Inspection Agency, 2018). In a study by Smith et al. (2008), four outbreaks in the U.S. for frozen, microwavable breaded chicken from 1998 through 2006, demonstrated that inadequate labeling, consumer's response to the labeling, and microwaving cooking are all essential factors. Although raw frozen breaded chicken is a more well-known example of such a product to be causing outbreaks, other frozen not-ready-to-eat product, such as pot pies in the U.S., have also shown to have outbreaks occurring in the past (Meyer et al., 2009). Proper food safety practices is crucial when preparing the frozen not-ready-to-eat products and cooking thoroughly by following the cooking instructions (Public Health Agency of Canada, 2018a). The labeling for cooking instructions and the state of the food as shown on the front packaging, serves as a defence mechanism to foodborne illness from inadequate food preparation, so it is critical that both are accurately and clearly depicted on the packaging.

\section{Consumers' Reading Behaviours on Labels}

\section{\& Ease of Reading}

In regards to the tendency of reading labels, a study conducted by Petrescu et al. (2014), indicates that students in Cluj-Napoca, a city in Romania, which represents a young and educated demographic, have a lower tendency to read labels as compared to expectations. A gap in the focus of consumers can be seen by most of the student's interest being directed to labels on expiration date, brand, quantity and price, whereas, information in processing method and preparation time, allergens and other information is less focused on. In addition, the study also shows that there is a significant difference in regards to the reading frequency of "other information" for consumers below and above 25 years old. This represents a potential difference in label reading behaviour of people in different age groups.

A study prepared for the U.S. Department of Agriculture's Food Safety and Inspection Service by Cates et al., (2001), revealed that a standardized labelling system was preferred for the consumers, as some of them were confused over whether a product needs to be further cooked completely due to the inconsistency in the labelling. For standardization, it was suggested and preferred by most consumers, that a logo for not ready-to-eat products or a color-coding scheme with a standardized phase should be created for both ready-to-eat and not-readyto-eat products. It was also mentioned that the printed text should be large enough to be visually seen by the consumer and standardized so it is consistently placed in 
the same location on the front of the

packaging. It was recommended at the end

of the study, for the U.S. Department of

Agriculture's Food Safety and Inspection

Service to evaluate the costs and benefit of

implementing a regulation or policy to

standardized labelling of not-ready-to-eat

meat and poultry products, so consumers

would know that the product requires

cooking before consumption.

In the study done by Mackey and Metz

(2009), it was discovered that the way the

printed information on the label is presented

can influence the ease of reading for the

consumers in Canada. It was found that

colour contrast in the prints, optimal

typography, the size of the fonts, the amount

of spacing between lines and the

layout/length of text lines can all influence

the ease of reading for consumers. When

these factors are not optimally implemented

in the labels, it can influence the ease of

finding relevant information on the package

and cause consumers to have to read

multiple times to find the information they

need, thereby, increasing their uncertainty in

the products (Mackey \& Metz, 2009).

Factors such as the kind of visual

presentation of the product on the package,

small sized fonts of the uncooked statement

in comparison to the other texts on the

package, package being discarded for

storage in the freezer and the fact that the

item was marketed as a quick meal option can mislead consumers into thinking that no cooking would be required (Hobbs et al., 2017). There are concerns in Canada for consumer's reading behaviour on labels that indicate if the product is ready-to-eat or notready-to-eat. The clarity of such printed text and the presentation of it can have a direct influence on how well the consumers can read and understand the labels.

\section{Materials and Methods}

\section{Materials Used}

The materials used was a laptop/desktop with internet access, along with Microsoft Word and Microsoft Excel. NCSS 12 was used for inferential statistical analysis of the data. SurveyMonkey Canada was used to create and host the survey. A smartphone and email was used for contacting the manufacturers. As well, the smartphone was used to take photos of the product in the store.

\section{Description of Standard Methods}

The standard method used was an online survey. The survey was distributed online through Reddit and includes 3 main sections alongside a consent form and cover letter on the internet posts, which entails what the scope and purpose of the study is, the personnel involved, the format of the survey, contact information, confidentiality issues, inclusion and exclusion criteria and any risk or benefit to participation. 
The first part of the survey compose of demographic questions to categorize respondents into groups of interest. The second part of the survey were identifications of the status of the product, ready-to-eat or not-ready-to-eat via product pictures and label statements, presented visually in the form of photos, as well as consumers' interpretation of specific label statements. The last section of the survey was an open-ended comment section to obtain respondents' opinions on how to improve clarity on labels.

The data collected through the survey was input into Microsoft Excel spreadsheet and transferred over to NCSS 12, a statistical tool software that can analyze and compare proportions via chi-square tests (NCSS 12 Statistical Software, 2019), in which Chisquare tests were conducted to analyze the data.

Emails or telephone calls were made to the manufacturers of the product that are included in the photos in the survey questions, to determine if the product is ready-to-eat or not-ready-to-eat.

\section{Inclusion and Exclusion Criteria}

All respondents of the online survey should be Canadian residents and have consented to the study after reading and understanding the consent form and cover letter. All nonCanadian residents are excluded from the study.

\section{Ethical Considerations}

Ethical considerations are in place throughout the course of the study, due to the study itself involving human beings. A cover letter was included in the internet postings to introduce the survey, and then the consent form was shown to participants at the start of the survey to inform them of any confidentiality issues and the goal of the research. The participants are also informed in the consent form that they are free to withdraw from the study at any time, and contact information to the investigator was given to them if they have any questions. The survey itself was reviewed by the BCIT Research Ethics Board, an elected group of faculty and staff in the institution that are in charge of reviewing and approving research studies in BCIT that involves human beings or human biological materials (BCIT, 2018). The board follows the Research Ethics for Human Participant Policy, which is based on the Tri-Council Policy Statement: Ethical Conduct for Research Involving Humans (BCIT, 2018).

\section{Results}

\section{Data Description}

The data collected was multichotomous ordinal and nominal data, in addition to that, an open-ended question, in the form of a comment box, was included at the end.

\section{Statistical Package Used}

Responses data was exported from SurveyMonkey to spreadsheet format in 
Microsoft Excel. SurveyMonkey and

Microsoft Excel organizes the data into

spreadsheets and into various graphs and

charts. The data organized in Microsoft

Excel was then transferred to NCSS 12 to

conduct Chi-square tests on.

\section{Descriptive Statistics}

A total of 139 respondents participated in

the survey, however, only 112 respondents

completed the entire survey (with the

exclusion of open-ended questions, which

were left as optional to complete). Out of the

139 respondents, 137 respondents completed

the demographic section of the survey.

For demographics, gender, $38.69 \%$ of the

respondents were male, $60.58 \%$ were female

and $0.73 \%$ identified themselves as "other".

For age, 1.46\% were under 20 years old,

$51.82 \%$ were between the ages of 20 to 39 ,

$35.04 \%$ were between the age of 40 to 59

and $10.95 \%$ were 60 or over 60 years old

and $0.73 \%$ of the respondents preferred not

to answer about age. For level of education,

$36.50 \%$ completed undergraduate degree,

$35.77 \%$ completed graduate degree, $16.06 \%$

completed some post-secondary, and

$22.63 \%$ were in high school, completed high

school or completed some post-secondary.

As well, 3.65\% have "other" as education

and $1.46 \%$ prefer not to answer. For the average number of times respondents visit the supermarket in a week, $62.77 \%$ visit 1 to 2 times a week, $19.71 \%$ visit less than once per week, and $16.06 \%$ visited between 3 to 7 times per week. $1.46 \%$ identified themselves as "other", indicating they visited more than 7 times per week. Aside from those demographic groups, $90.51 \%$ of the respondents had English as their native language and $9.49 \%$ had "other" as their native language.

The following charts summarizes the descriptive statistics for the product identification portion of the survey.

Figure 1. Responses to label interpretation of food products based on front of packaging photos taken.

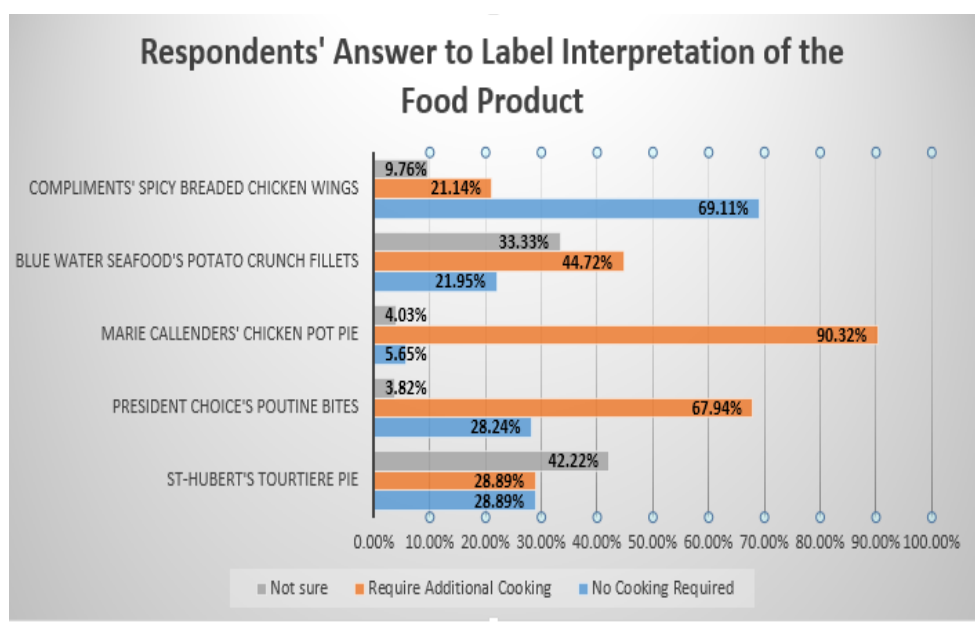


Table 1. Descriptive analysis of label interpretations with no products shown

\begin{tabular}{|c|c|c|c|c|c|}
\hline & $\begin{array}{l}\text { Product } \\
\text { requires no } \\
\text { cooking prior } \\
\text { to being } \\
\text { ready-to-eat } \\
\text { with option } \\
\text { to warm up } \\
\text { to taste } \\
\text { preference }\end{array}$ & $\begin{array}{l}\text { The food } \\
\text { product } \\
\text { requires } \\
\text { additional } \\
\text { cooking prior } \\
\text { to being } \\
\text { ready-to-eat }\end{array}$ & $\begin{array}{l}\text { Can be either } \\
\text { ready-to-eat } \\
\text { or not-ready- } \\
\text { to-eat } \\
\text { depending on } \\
\text { the type of } \\
\text { product }\end{array}$ & Not sure & Total \\
\hline $\begin{array}{l}\text { Product } \\
\text { presented as } \\
\text { a cooked } \\
\text { product in the } \\
\text { front of } \\
\text { package and } \\
\text { is not } \\
\text { labelled with } \\
\text { any specific } \\
\text { statement. I } \\
\text { interpret this } \\
\text { to indicate... }\end{array}$ & $\begin{array}{l}41.23 \%(47 \\
\text { respondents) }\end{array}$ & $\begin{array}{l}8.77 \%(10 \\
\text { respondents) }\end{array}$ & $\begin{array}{l}44.74 \%(51 \\
\text { respondents) }\end{array}$ & $\begin{array}{l}5.26 \%(6 \\
\text { respondents) }\end{array}$ & $\begin{array}{l}114 \\
\text { respondents }\end{array}$ \\
\hline $\begin{array}{l}\text { The product } \\
\text { is labelled as } \\
\text { heat } \\
\text { thoroughly. I } \\
\text { interpret this } \\
\text { to indicate... }\end{array}$ & $\begin{array}{l}26.32 \%(30 \\
\text { respondents })\end{array}$ & $\begin{array}{l}55.26 \%(63 \\
\text { respondents })\end{array}$ & $\begin{array}{l}14.04 \%(16 \\
\text { respondents) }\end{array}$ & $\begin{array}{l}4.39 \%(5 \\
\text { respondents) }\end{array}$ & $\begin{array}{l}14 \\
\text { respondents }\end{array}$ \\
\hline $\begin{array}{l}\text { The product } \\
\text { is labelled s } \\
\text { cook } \\
\text { thoroughly. I } \\
\text { interpret this } \\
\text { to indicate... }\end{array}$ & $\begin{array}{l}1.72 \%(2 \\
\text { respondents) }\end{array}$ & $\begin{array}{l}95.69 \%(111 \\
\text { respondents) }\end{array}$ & $\begin{array}{l}1.72 \%(2 \\
\text { respondents) }\end{array}$ & $\begin{array}{l}0.86 \%(1 \\
\text { respondents) }\end{array}$ & $\begin{array}{l}116 \\
\text { respondents }\end{array}$ \\
\hline $\begin{array}{l}\text { The product } \\
\text { is labelled as } \\
\text { uncooked. I } \\
\text { interpret this } \\
\text { to indicate... }\end{array}$ & $\begin{array}{l}1.74 \%(2 \\
\text { respondents) }\end{array}$ & $\begin{array}{l}96.65 \%(110 \\
\text { respondents) }\end{array}$ & $\begin{array}{l}2.61 \%(3 \\
\text { respondents) }\end{array}$ & $\begin{array}{l}0 \%(0 \\
\text { respondents })\end{array}$ & $\begin{array}{l}115 \\
\text { respondents }\end{array}$ \\
\hline $\begin{array}{l}\text { The product } \\
\text { is labelled as } \\
\text { fully cooked. } \\
\text { I interpret } \\
\text { this to } \\
\text { indicate... }\end{array}$ & $\begin{array}{l}78.45 \%(91 \\
\text { respondents) }\end{array}$ & $\begin{array}{l}5.17 \%(6 \\
\text { respondents) }\end{array}$ & $\begin{array}{l}15.52 \%(18 \\
\text { respondents) }\end{array}$ & $\begin{array}{l}0.86 \%(1 \\
\text { respondents) }\end{array}$ & $\begin{array}{l}116 \\
\text { respondents }\end{array}$ \\
\hline
\end{tabular}


In their replies, the St-Huberts' Tourtiere Pie and Marie Callenders' Chicken Pot Pie were identified as not precooked (St-Hubert, personal communication, Jan 16, 2019). For the chicken pot pie specifically, the dough was not cooked but the meat was cooked inside (Conagra Brand, personal communication, Jan 30, 2019). For the Blue Water Seafood Potato Crunch fillet and Compliment's Breaded Chicken Wings it was clearly stated on the label that it was uncooked and fully cooked, respectively. For the President Choice's Poutine Bites the product was identified as being precooked (President Choice, personal communication, Jan 17, 2019).

Out of the 57 comments, 9 respondents left comments mentioning the back of the box, 9 mentioned something related to the font/color clarity on the package, 7 mentioned detailed or clear cooking instructions should be required, and 26 responses mentioned something with the statements itself. Out of the 26 responses some mentioned having standardization, clear labels, or specific wordings for uncooked products. A few of the responses identified the current labels as adequate/clear enough for identification.

\section{Inferential Statistics}

Chi-Square tests were conducted comparing demographic groups and the accuracy of the respondent's interpretation of labels. The accuracy of respondents was determined based on how many (out of 5 questions) of the label interpretation questions, provided with the photo of the product, they can accurately identifies. Chi-square tests were selected due to the data being nominal, and for determining if there's an association between multiple groups (Duignan, 2016).

Table 2. Chi-Square Tests Conducted for Survey of Frozen Products vs. Label Interpretation

\begin{tabular}{|c|c|c|c|}
\hline Null Hypothesis & Test Used & P-value & Conclusion \\
\hline $\begin{array}{l}\text { H0: There is no association } \\
\text { between consumers' } \\
\text { interpretation of frozen food } \\
\text { products labels and age } \\
\text { Ha: There is an association } \\
\text { between consumers' } \\
\text { interpretation of frozen food } \\
\text { products labels and age }\end{array}$ & $\begin{array}{l}\text { Chi-Square } \\
\text { Test }\end{array}$ & 0.23241 & $\begin{array}{l}\text { The p-value is greater than } \\
0.05, \text { therefore do not reject } \\
\text { null hypothesis and } \\
\text { conclude that there's no } \\
\text { association between } \\
\text { consumers' interpretation } \\
\text { of frozen food products } \\
\text { labels and age }\end{array}$ \\
\hline
\end{tabular}




\begin{tabular}{|c|c|c|c|}
\hline $\begin{array}{l}\text { H0: There is no association } \\
\text { between consumers' } \\
\text { interpretation of frozen food } \\
\text { products labels and level of } \\
\text { education } \\
\text { Ha: There is an association } \\
\text { between consumers' } \\
\text { interpretation of frozen food } \\
\text { products labels and level of } \\
\text { education }\end{array}$ & $\begin{array}{l}\text { Chi-Square } \\
\text { Test }\end{array}$ & 0.39832 & $\begin{array}{l}\text { The p-value is greater than } \\
0.05, \text { therefore do not reject } \\
\text { null hypothesis and } \\
\text { conclude that there's no } \\
\text { association between } \\
\text { consumers' interpretation } \\
\text { of frozen food products } \\
\text { labels and level of } \\
\text { education }\end{array}$ \\
\hline $\begin{array}{l}\text { H0: There is no association } \\
\text { between consumers' } \\
\text { interpretation of frozen food } \\
\text { products labels and the average } \\
\text { number of times they visit the } \\
\text { supermarket in a week } \\
\text { Ha: There is an association } \\
\text { between consumers' } \\
\text { interpretation of frozen food } \\
\text { products labels and the average } \\
\text { number of times they visit the } \\
\text { supermarket in a week }\end{array}$ & $\begin{array}{l}\text { Chi-Square } \\
\text { Test }\end{array}$ & 0.99141 & $\begin{array}{l}\text { The p-value is greater than } \\
0.05 \text {, therefore do not reject } \\
\text { null hypothesis and } \\
\text { conclude that there's no } \\
\text { association between } \\
\text { consumers' interpretation } \\
\text { of frozen food products } \\
\text { labels and the average } \\
\text { number of times they visit } \\
\text { the supermarket in a week }\end{array}$ \\
\hline $\begin{array}{l}\text { H0: There is no association } \\
\text { between consumers' } \\
\text { interpretation of frozen food } \\
\text { products labels and their gender } \\
\text { Ha: There is an association } \\
\text { between consumers' } \\
\text { interpretation of frozen food } \\
\text { products labels and their gender }\end{array}$ & $\begin{array}{l}\text { Chi-Square } \\
\text { Test }\end{array}$ & 0.40879 & $\begin{array}{l}\text { The p-value is greater than } \\
0.05, \text { therefore do not reject } \\
\text { null hypothesis and } \\
\text { conclude that there's no } \\
\text { association between } \\
\text { consumers' interpretation } \\
\text { of frozen food products } \\
\text { labels and their gender }\end{array}$ \\
\hline
\end{tabular}




\section{Discussion}

\section{Purpose}

The purpose of the study "Label Perception of Frozen Ready-to-Eat Products and Frozen Not-Ready-to-Eat Product" was to examine the demographics of Canadian residents and assess their ability to determine the state of frozen food products as precooked or raw. In addition, the residents' knowledge of general statements that are found on frozen products such as "cooked", "uncooked", or "cook thoroughly" are assessed as well.

\section{Demographics}

The demographics can be used to target specific age or level of education groups when designing clear and suitable labelling statements. Health campaigns or announcements to promote more awareness for frozen product consumption can also be directed towards this specific demographics. This demographics data can also be utilized towards cooking instructions stated at the back of the box. According to the report by Agriculture and Agri-Food Canada (2012), global consumer trends indicate that consumers in the age of 18 to 34 in countries like the U.S. or U.K., along with consumers in the age group of 35 to 64 are more likely to purchase or favour frozen foods. A news article by Chris Powell (2015), also indicate that Canadian dads are a significant portion of frozen meal consumptions. From the results of the survey, the majority of the demographic audience is young adult to middle age group, with adequate English proficiency and high level of education, the language used in the instructions can be more technical or specific if necessary. However, it is important to keep in mind that the survey was only available online, so certain age groups such as seniors or children might not be able to access it as readily as others. The platform this was posted on, Reddit, and the sub-Reddit that was posted on, might influence the type of respondents surveyed. The formality of the post, along with the academic nature of the survey, might had driven away participants of lower education.

\section{Product Identification}

For the first photo, a Tourtière pie product with no statement was given. Since there was a lack of statement, it was expected that the "not sure" option would be chosen the most, and the results of an even split of the other two options beside "not sure" indicate uncertainty about the product's status. Since the pie itself is not fully precooked, this can lead to potential consumption of undercooked pie when it is being prepared by consumers.

The second photo was a poutine bite product, with the statement "heat thoroughly" on the package. Most of the respondents perceives "heat thoroughly" as require cooking. However, the product itself is actually precooked. This indicate a 
potential misinterpretation when statements

that suggests "heating" or cautious statement that say "thoroughly" is involved. Since the product itself is precooked, additional cooking won't cause a problem in regards to health concerns, but it indicate that consumers' ability to interpret label statements are lacking.

The third photo is a chicken pot pie, with the statement "cook thoroughly" on the package. Majority of the respondent chose the correct answer of the product being "require additional cooking", which indicate that the statement "cook thoroughly" was accurately identified by respondent as a product that require additional cooking. This indicate that common label statements such as "cook thoroughly" that appears a lot on packaging is well understood by consumers.

The fourth photo is potato crunch fish fillets, with the statement "uncooked" on the package. A clear statement "uncooked" was identified as raw or partially cooked by less than half the respondents. It was expected that a higher percentage of the respondent would choose "additional cooking" since "uncooked" should be relatively clear to indicate the product is raw. However, potentially due to the small font size and lack of color contrast of the statement on the package, a lower percentage was shown for the option "require additional cooking". For the fish fillet, the statement was relatively small in size and placed in the corner area. The statement is significantly smaller in comparison to the text "Breaded Alaska Pollock Fillet" directly below it. This might had cause the respondent to be distracted by the "Breaded Alaska Pollock Fillet" text and missed the "uncooked" label above. For frozen breaded products, they can give off a similar appearance to a ready-to-eat product when it is actually still raw (Newstex, 2015). For public health significance, this can potentially cause consumers to undercook the product, thinking it was precooked. The last photo is spicy breaded chicken wings, with the statement "fully cooked" on the package. Since the statement is clear and straightforward, it was expected that the majority of the respondents would choose "require no cooking" as their choice.

However, only $69 \%$ of the respondents chose this option. This might had been due to the statement itself being put together along with the terms "seasoned" and " $15 \%$ meat protein", so consumers might had missed it when they were reading the package. Since the product itself is already fully cooked, there's no significant health concerns in consuming the product even if it's undercooked.

The respondents were asked to identify label statements such as "cook thoroughly" separately without photos of the product. The trends of the answers follow similarly to 
the product photo identification question. However, the option "uncooked" and "fully cooked" was more accurately determined by respondents to be "require additional cooking" and "require no cooking", respectively, in comparison to the lower percentage indicated in earlier questions with the product photo presented. This might be due to issues with the visual appearance, having a smaller font size or color contrast, rather than the statement itself being misinterpreted. Which is why when a clear statement was presented to be identified, a larger percentage of respondents chose the correct answer.

NCSS 12 (2018) was used to conduct the analysis for the four hypothesis comparing demographic groups to the accuracy of the respondents' interpretation of the products based on its labelling descriptions. No association was found between any of the demographic groups to the product labelling interpretations. This indicate that neither age, gender, level of education, or average number of supermarket visits per week affected the accuracy of the respondents' label interpretations of the frozen products.

For the open ended comments, several responses indicate that a clear standardized label would be beneficial to have. Clear, large statements or cooking instructions along with specific temperature were suggested by some. It would appear that having simple and clear statements such as "fully cooked" or "raw/uncooked" would be the most favourable option for some respondents. A lot of the comments mentioned the back of the box or referring to cooking instructions. This can potentially indicate a heavier reliance on the cooking instructions on back of the box to determine if a product is precooked. A clear standardized label can serve to enhance the ability for consumers to accurately interpret a product as being cooked or raw.

\section{Knowledge Translation}

As more outbreaks or recalls occurs due to frozen food products, the clarity of labelling on the package is critical to ensure that the product is prepared adequately by consumers. The front of the package is the first line of defense, and the first thing consumers will look at before purchasing a product. If consumers can accurately determine if the product is precooked or not at this stage, it can influence their decision in purchasing the product and their method of preparation before consumption. This study can be used to identify if the current labelling system is adequate to ensure that consumers fully understand if the product they purchase is precooked or not. It can assist guidelines and legislations in assessing the effectiveness of the current labelling system. It can also provide assistance towards formulating a standardized labelling 
statements by identifying which of the current statements are the most confusing for the consumers. The open ended response in the study can also assist in identifying what the public are looking for in clear labelling and what their opinions are for improving the labelling.

\section{Limitations}

The study was heavily influenced by time. The number of responses gathered could have been higher if more time was allowed. This would allow a higher proportion of respondent to have different demographic categories to be included in the study, potentially changing the result of the data analysis of the four hypothesis. In addition, since the survey was distributed online, the demographic group could have been affected. This would be limited to populations with English proficiency and ability to access the internet. Since the distributing platform was Reddit, there's potentially bias of respondents for the subReddit that was posted. The sub-Reddit selected would indicate that the respondent are already self-interested in the topic, and can cause a selection bias (Shatz, 2017). For example, in posting at /r/Samplesize, the respondent of that sub-Reddit was biased towards people who actively want to participate in surveys. Finally, wordings and understanding of the question's context was a significant factor in the survey. There was several comments expressing confusion towards the questions. As well, some of the products are sold in stores and respondents might have previous knowledge regarding the product, which would affect how accurately they can identify the products.

For recommendations, more time can be allotted to complete the study, which would allow a larger sample size. In addition, other types of surveying such as in person interviews can be considered in contrast to online surveys. The questions can be worded simpler and the questions can be reduced to avoid fatigue of the respondents.

\section{Future Research}

Future Research can include

- A survey of consumer's reliance on front of package to identify frozen products as being precooked or raw in comparison to back of package

- A survey of the visual presentation of labels on packaging - The effect of size of the font or color of the font in contrast to the background versus the noticeability by consumers.

- An observation trial examining how consumers prepare precooked or raw frozen food products with the cooking instructions given. 
- A survey of dry storage products and if consumers know its raw or not- e.g. raw flour

\section{Conclusion}

Clear labels on packaging is the first line of defense towards consuming undercooked foods by assisting consumers towards determining if a frozen product is precooked or not. This help prevent the products from being undercooked, thus preventing foodborne illness from the consumption of raw/undercooked food. This study assesses the clarity of labelling statements on the current market along with the accuracy of consumers' interpretation of those labels. The study found that neither age, gender, level of education, or number of weekly supermarket visits have an effect on how consumers' interpretation of labels on frozen food products. Although cooking statements that clearly state "uncooked" or "fully cooked" are generally understood by consumers. Other more ambiguous statements such as "heat thoroughly" or a lack of statement on the package completely, indicate some degree of uncertainty amongst consumers in determining if the product is cooked or raw. It would appear that the public favours clear and straightforward labelling statements, as identified in some open responses from the participants. The study identifies potential problems with the ambiguity of some (or lack of) label statements and potential issues with how the statement is presented to be visually noticeable to consumers. However, further research is required to better understand this issue and assess consumers' opinion on how to improve those labels.

\section{Acknowledgements}

The author thank the British Columbia Institute of Technology, Environmental Health Program; Dale Chen and Helen Heacock for their assistance and support throughout the project. The author would also like to thank the British Columbia Centre for Disease Control; Lorraine McIntyre for their assistance in this research project.

\section{Competing Interest}

The author declares that they have no competing interest 


\section{References}

Associated Press. (2008, Oct 6). Nuking frozen meals can make you sick. NBC News. Retrieved from

http://www.nbcnews.com/id/27055169/ns/he alth-food safety/t/nuking-frozen-meals-canmake-you-sick/\#.W8jx mhKjIU

BCIT: British Columbia Institute of Technology. (2018). Applied Research at BCIT. Retrieved from https://www.bcit.ca/appliedresearch/ethics/

Canada. Agriculture and Agri-Food Canada. International Markets Bureau, \& Canadian Government EBook Collection. (2012).

Global consumer trends - age demographics. Ottawa: Agriculture and Agri-Food Canada.

Canadian Food Inspection Agency. (2018). List of recalls of frozen raw breaded chicken products due to Salmonella: from July 2017 to present. Retrieved from http://inspection.gc.ca/food/information-forconsumers/food-safety-investigations/list-ofrecalls-of-frozen-raw-breaded-chickenprod/eng/1536716947924/1536717030715

Cates, S.C., Carter-Young, H., Gledhill, E.C. (2001). Consumer Perceptions of NotReady-to-Eat Meat and Poultry Labeling Terminology. Research Triangle Institute. Retrieved from https://www.fsis.usda.gov/wps/wcm/connect /f21b513b-3866-46cf-9c42aa805680c2c3/Consumer+Perceptions_Volu $\underline{\text { me1.pdf?MOD=AJPERES }}$

Duignan, J. (2016). Chi-square. $A$ Dictionary of Business Research Methods. : Oxford University Press. Retrieved 18 Feb. 2019, from

http://www.oxfordreference.com.ezproxy.lib rary.ubc.ca/view/10.1093/acref/9780191792 236.001.0001/acref-9780191792236-e-76.

Hobbs, J. L., Warshawsky, B., Maki, A., Zittermann, S., Murphy, A., Majury, A., \& Middleton, D. (2017). Nuggets of wisdom:
Salmonella enteritidis outbreaks and the case for new rules on uncooked frozen processed chicken. Journal of Food Protection, 80(4), 703.

Kalyoussef, S., DO, \& Feja, Kristina N., MD, MPH. (2014). Foodborne illnesses. Advances in Pediatrics, 61(1), 287-312. doi:10.1016/j.yapd.2014.04.003

Levesque L. (2017). Canadian food habits, attitudes towards meals are shifting:

Dalhousie study. HuffPost Canada.

Retrieved from

https://www.huffingtonpost.ca/2017/05/19/c anadian-food-habits n 16704852.html

Mackey, M. A., \& Metz, M. (2009). Ease of reading of mandatory information on canadian food product labels. International Journal of Consumer Studies, 33(4), 369-381. doi:10.1111/j.14706431.2009.00787.x

Meyer, S., Smith, K., Azzam, I., Sowadsky, R., Williams, I., Henao, O., . . Mody, R. (2009). Multistate outbreak of salmonella infections associated with frozen pot PiesUnited states, 2007. Jama, 301(3), 264-266. doi:10.1001/jama.301.3.264

NCSS 12 Statistical Software. (2019).

Crosstabs and Analysis of Proportions in NCSS. Retrieved from https://www.ncss.com/software/ncss/crossta bs-and-analysis-of-proportions-in-ncss/

NCSS 12 Statistical Software (2018). NCSS, LLC. Kaysville, Utah, USA, ncss.com/software/ncss.

Newstex. (2015). Food safety news Aspen foods expands recall of frozen, raw, stuffed and breaded chicken entrées. Newstex Trade \& Industry Blogs. Retrieved from http://ezproxy.library.ubc.ca/login?url=https ://search-proquestcom.ezproxy.library.ubc.ca/docview/171854 9153? accountid $=14656$

Petrescu, D., Mihăiescu, T., Maxim, A., Vârban, D., Odagiu, A., Proorocu, M., \& 
Coadă, C. A. (2014). Consumers' food label reading behaviour. Advances in Agriculture \& Botanics, 6(1), 57-69.

Powell, C. (2015). Frozen meal category challenged by health-focused Canadians. Canadian Grocer. Retrieved from http://www.canadiangrocer.com/topstories/frozen-meal-category-challenged-byhealth-focused-canadians-55295

Public Health Agency of Canada. (2018a). Public Health Notice - Outbreaks of Salmonella infections linked to frozen raw breaded chicken products. Retrieved from https://www.canada.ca/en/publichealth/services/public-healthnotices/2018/outbreak-salmonellainfections-linked-frozen-raw-breadedchicken-products.html

Ready Meals In Canada. (2015). (). London: Euromonitor International Ltd. Retrieved from ABI/INFORM Collection Retrieved from http://ezproxy.library.ubc.ca/login?url=https ://search-proquestcom.ezproxy.library.ubc.ca/docview/175320 $\underline{7258 ? \text { accountid }=14656}$

Shatz, I. (2017). Fast, free, and targeted: Reddit as a source for recruiting participants online. Social Science Computer Review, 35(4), 537-549. doi:10.1177/0894439316650163

Smith, K. E., Medus, C., Meyer, S. D., Boxrud, D. J., Leano, F., Hedberg, C. W., . . Danila, R. N. (2008). Outbreaks of salmonellosis in minnesota (1998 through 2006) associated with frozen, microwaveable, breaded, stuffed chicken products. Journal of Food Protection, 71(10), 2153-2160. doi:10.4315/0362-028X71.10 .2153

Tang, J., Hong, Y., Inanoglu, S., \& Liu, F. (2018). Microwave pasteurization for readyto-eat meals. Current Opinion in Food Science, doi:10.1016/j.cofs.2018.10.004 
Reference to Complete Paper

Cheung, C. (2019). Label Perception of Frozen Ready-to-Eat Products and Frozen Not-Ready-toEat Product. BCIT Environmental Health Journal. 